\title{
CAMINHOS METODOLÓGICOS EM DEBATE - UMA EXPERIÊNCIA INVESTIGATIVA EM ESPAÇOS TRANSFRONTEIRIÇOS
}

\author{
Helenara Silveira Fagundes ${ }^{1}$, Vera Maria Ribeiro Nogueira ${ }^{2}$ e Ineiva Terezinha Kreutz ${ }^{3}$ \\ ${ }^{1 \text { e } 2}$ Universidade Federal de Santa Catarina, Brasil. ${ }^{1}$ helenarasf@hotmail.com, ${ }^{2}$ veramrn@gmail.com \\ ${ }^{3}$ Universidade Estadual do Oeste do Paraná, Brasil. ineivakreutz@gmail.com
}

\begin{abstract}
Resumo. Este artigo coloca em debate as opções metodológicas adotadas para o projeto "Cooperação transfronteiriça e cidadania social: ampliação, impasses e limites". O objetivo do artigo é refletir sobre os caminhos metodológicos a serem utilizados nesta pesquisa para aprimorar instrumentos e técnicas de coleta e análise de dados. A pesquisa será exploratória e se utilizará de pesquisa documental e entrevistas em profundidade. Os participantes da pesquisa serão os gestores e profissionais da política de saúde e da assistência social. As ferramentas do Software WebQDA serão adotadas para análise dos dados devido à viabilidade de interação entre os pesquisadores, garantindo a confiabilidade de estudos multicêntricos.
\end{abstract}

Palavras-chave: Política de Saúde; Política de Assistência Social; Fronteira; Metodologia; Estudos Multicêntricos.

\section{METHODOLOGICAL PATHS IN DEBATE - AN INVESTIGATIVE EXPERIENCE IN FRONTIER SPACES}

\begin{abstract}
This article discusses the methodological options adopted for the project Cross-border cooperation and social citizenship: expansion, impasses and limits". The objective is to reflect the methodological paths used in this research to improve instruments and techniques for data collection and analysis in the future. The research will be exploratory and will use documentary research and interviews. The research subjects will be the managers and professionals of the health and social assistance policy. The tools of the WebQDA Software will be adopted for data analysis due to the feasibility of interaction between researchers, ensuring the reliability of multicenter studies.
\end{abstract}

Keywords: Health Policy; Social Assistance Policy; Border; Methodology; Multicenter Studies.

\section{INTRODUÇÃO}

O trabalho aborda a proposta metodológica do projeto "Cooperação transfronteiriça e cidadania social: ampliação, impasses e limites" com vistas a ampliar o debate sobre as questões metodológicas a serem adotadas no desenvolvimento do estudo. Este texto situase como uma meta análise e uma avaliação ex-ante sobre a metodologia para coleta de dados. O objetivo do texto, portanto, é colocar em debate os caminhos metodológicos desta pesquisa para futuramente aprimorar instrumentos e técnicas de coleta e análise de dados. Esta preocupação leva em conta a complexidade de regiões fronteiriças internacionais marcadas pela divergência nas organizações jurídico, administrativas e programáticas em um espaço comum de vivência. Na área da fronteira, o principal óbice é a exacerbação da desigualdade territorial que atua perversamente e marca o processo de exclusão sanitária e 
déficits na proteção socioassistencial. A fruição do direito à saúde e assistência social implica em efeitos concretos no âmbito das políticas públicas nas duas franjas das fronteiras internacionais, exigindo definições e planejamento conjuntos entre os gestores das cidades gêmeas. Estes devem ser construídos através de agendas definidas de forma conjunta entre os poderes municipais e os representantes da população, sendo estas definições concernentes a atores políticos competentes com proposições que realmente considerem as necessidades locais. Incorpora-se, assim, ao direito universal a saúde e a proteção social, a análise da determinação social do processo saúde-doença e os impasses para proteção social. Apreender esta dinâmica transfronteiriça impõe pensar e adequar procedimentos metodológicos que deem conta de resgatar fenômenos próprios destes espaços geográficos. O texto apresenta aspectos do projeto necessários para a apreensão dos caminhos a serem percorridos para a execução da pesquisa e assinala que se irá utilizar da pesquisa documental, entrevistas em profundidade e se empregará a ferramenta tecnológica do software webQDA na organização e análise dos dados. O artigo apresenta um breve contexto da região estudada, a proposta metodológica e as conclusões.

\section{CONTEXTO DA REGIÃO OBJETO DE ESTUDO}

Este artigo coloca em debate as opções metodológicas adotadas para o projeto "Cooperação transfronteiriça e cidadania social: ampliação, impasses e limites". O projeto de pesquisa em análise tem como foco apreender como se processa a ação dos sujeitos políticos públicos locais - gestores e profissionais - em relação à cooperação transfronteiriça, considerada um dos elementos decisivos para garantir a cidadania social em relação à proteção integral a saúde e a assistência social da população residente na área da fronteira. Esta cooperação, para além do plano discursivo e legal, se concretiza na inclusão dos cidadãos transfronteiriços que demandam ações e serviços em municípios que não o de sua residência. Esta inclusão, prevista nos acordos assinados pelos países integrantes do Mercado Comum do Sul (MERCOSUL) e internalizados na ordem jurídica dos Estados parte, não vem sendo obtida nas fronteiras do bloco, com raras experiências exitosas.

Desta afirmativa decorre a indagação inicial que motivou este estudo: se existe a garantia de acesso no plano legal/jurídico, das demandas dos cidadãos, porque tal não ocorre? Não se desconhece que a cooperação transfronteiriça sofre o impacto de vários fatores, tais como as distinções entre os países quanto à forma orgânica do aparato estatal subnacional, os 
níveis de complexidade diferenciados dos sistemas de proteção social e saúde, a relação do nível local com o nacional e o protagonismo dos gestores e profissionais.

Entretanto, resultados de estudos anteriores apontam a relevância inconteste dos sujeitos políticos do nível local para o êxito ou fracasso das políticas públicas para inclusão dos não nacionais. Como não foram identificados estudos nesta perspectiva, definiu-se como objetivo geral apreender como se processa a mediação dos sujeitos políticos locais na produção de políticas de saúde e assistência social, evidenciando os avanços, impasses e limites para a cooperação transfronteiriça na linha de fronteira dos países do MERCOSUL. Os objetivos específicos principais preveem: identificar como ocorre a apropriação dos dispositivos nacionais e das normativas do MERCOSUL relacionadas à demanda estrangeira; conhecer as competências e as estratégias utilizadas pelos gestores e profissionais na ação transfronteiriça; apreender como as mediações realizadas expressam uma determinada concepção de cidadania social; avaliar em que medida a complexidade dos sistemas de saúde e assistência social disponíveis interfere na cooperação transfronteiriça; resgatar as experiências exitosas de cooperação transfronteiriça, assinalando os seus fatores determinantes.

As metas, a serem alcançadas dos dois lados da fronteira, compreendem a descrição da organização institucional dos sistemas locais de saúde e assistência social e dos serviços prestados, a atualização da legislação transfronteiriça (legislação nacional, acordos e pactos entre os países e as decisões do MERCOSUL) no campo da saúde e assistência social, o estabelecimento do perfil profissional e as vinculações éticas e políticas dos agentes estatais, a reconstrução da dinâmica processual da ação dos agentes locais na implementação das políticas de saúde e assistência social, favorecendo ou não a construção da dimensão social da cidadania. Os espaços fronteiriços são identificados como zonas de alta porosidade e fluxo contínuo de bens, serviços e pessoas, ou seja, possui a concepção de um espaço comum diverso do nacional. São territórios vinculados à identidade nacional que se dilui, associadas às manifestas situações de dubiedade, de diferença versus integração, nas quais, além de contrastes de língua e de cultura, dá-se a convivência cotidiana entre sistemas políticos, monetários, de segurança, de saúde e de proteção social distintos. As fronteiras, para serem entendidas em suas complexas determinações, exigem uma visão de totalidade, superando a visão tradicional de limite territorial e área de segmentação política e social. 


\section{PROPOSTA METODOLÓGICA}

As opções metodológicas decorrem das questões a serem abordadas, no caso específico os sujeitos políticos do âmbito governamental local (gestores e profissionais dos setores da saúde e assistência social) face a cooperação transfronteiriça e a dimensão social da cidadania, entendida como o conjunto de direitos e obrigações que possibilita a participação igualitária de todos os membros de uma comunidade nos seus padrões básicos de vida. Em sociedades capitalistas democráticas há uma permanente tensão entre a cidadania individual e a dimensão social da cidadania, visto implicar em ajustes entre interesses contraditórios entre capital e trabalho. Mantém-se o eixo orientador dos estudos anteriores, ou seja, o acesso aos bens e serviços de saúde e assistência social através de políticas públicas, por ser um direito de cidadania e não de necessidade (Telles, 1994). Portanto, deve incorporar valores justos e universais materializados unicamente através de práticas profissionais e de formas de gestão institucional que espelhem estes valores. Esta afirmação não significa tratar a gestão pública isolada das relações econômicas e de poder determinantes das formas políticas locais e com alto impacto na construção da cidadania social. Mas, sim, entender a gestão pública, quando efetivamente democrática ${ }^{1}$, como um dos componentes essenciais para o acesso e fruição do direito à saúde, situando-a como a estrutura substantiva das políticas públicas. Portanto, as questões que orientam o projeto atual têm como referência ética os valores acima indicados e decorrem dos resultados de estudos desenvolvidos ${ }^{2}$ pela proponente, especialmente a consultoria ${ }^{3}$ ao Instituto Social do MERCOSUL ${ }^{4}$, em 2017, que aprofundou o diagnóstico da realidade fronteiriça nas áreas da saúde, educação, previdência e assistência social.

O aprofundamento da compreensão sobre o processo de implementação trouxe outras nuances a serem apreendidas como, por exemplo, a indicada por Mégie (2010) quanto à impossibilidade de uma abordagem exclusivamente top-down ou botton-up, devendo-se

\footnotetext{
1 Assume-se como democrática, a gestão que incorpora valores de igualdade e justiça de forma universal, mantendo o sentido público como diretriz central e com a participação efetiva da sociedade.

2 Os projetos mencionados são: "Fronteira MERCOSUL: um estudo sobre o direito à saúde"; "A institucionalidade dos sistemas locais de saúde na linha da fronteira MERCOSUL"; "O direito à saúde na perspectiva da população residente na linha da fronteira MERCOSUL"; "A implementação do Programa SIS FRONTEIRAS e do Pacto pela Saúde - perspectivas para a ampliação do direito à saúde aos usuários estrangeiros na Fronteira Arco Sul"; "Ampliando o direito à saúde - experiências de cooperação entre sistemas e/ou serviços de saúde em linha de fronteira"; "Uma questão e duas temporalidades: direito à saúde na fronteira MERCOSUL - 2003-2013"; "Pactos, protocolos e o protagonismo dos atores políticos locais: impasses e condicionantes para o acesso aos bens e serviços de saúde na linha de fronteira Arco Sul"; "Sistema Único de Assistência Social e Proteção de Cidadãos Transfronteiriços: um estudo em cidades gêmeas da fronteira gaúcha" e; "Elementos intervenientes na proteção social de transfronteiriços indocumentados na fronteira Arco Sul".

${ }^{3}$ A consultoria foi realizada entre junho e outubro de 2017 , financiada pelo Instituto Social do MERCOSUL.

${ }^{4}$ O Instituto Social do MERCOSUL é a uma instancia técnica regional de pesquisa e fomento no campo das políticas sociais do MERCOSUL.
} 
considerar o conjunto de atores da ação pública e suas diferentes interdependências (verticais e horizontais). Esta perspectiva interacionista oferece a possibilidade de restituir a dimensão multinível e transversal da ação pública. Portanto, um mapeamento preciso de níveis de ação, "[...] bem como o papel e os interesses dos atores em presença é um trabalho essencial para compreender as interações sociais que estruturam o espaço público" (Mégie, 2010, p. 349). Nesta estruturação, os diferentes níveis de ação pública são representativos e devem ser levados em conta, conforme a indicação de Borraz \& Guiraudon (2010). Cada nível dispõe de competências diversas e as mudanças de escala do global ao local, passando pelo nacional, tem um impacto na formulação da ação pública e na determinação da cidadania. Ou seja, a descentralização ao mesmo tempo em que leva a uma fragmentação da ação pública, pode alterar o estatuto de cidadania em relação a garantia de direitos face à discricionariedade dos agentes locais na medida em que novas decisões são tomadas no momento da implementação. Assim, torna-se fundamental avaliar como as decisões nacionais são reconfiguradas no plano local, tornando-o também o "lugar de fabricação da ação pública" (Zittoun, 2013; Aikes \& Rizzotto, 2018; Mégie, 2010).

O desconhecimento sobre as estruturas de gestão dos municípios vem sendo reafirmado por autores vinculados ao tema, alertando a predomínio de pesquisas sobre as burocracias nacionais, do alto escalão, em detrimento da análise do poder local (Cavalcante, Camões \& Knop, 2015; Cavalcante \& Lotta, 2015; Oliveira \& Abrucio, 2011; Aikes \& Rizzotto , 2018). Também se desconhecem as posições hierárquicas nas estruturas administrativas das Secretarias Municipais de Saúde e da Assistência Social no Brasil e as equivalentes na Argentina, Paraguai e Uruguai, que determinam a parcela de poder organizacional e autonomia que dispõem para implementar a cooperação transfronteiriça via acordos paradiplomáticos.

É no intento de preencher esta lacuna que se localiza este projeto, entendendo os sujeitos profissionais não como um corpo amorfo, mas como sujeitos políticos cujas iniciativas podem expressar práticas inovadoras de gestão, fortalecedoras da participação popular nas decisões e no acompanhamento das políticas locais (Tumelero, 2015). A gestão quando vinculada a área social, pode ser um instrumento de universalização e aprofundamento de direitos, como uma dimensão do processo de democratização voltada para a construção de uma sociedade efetivamente emancipada (Souza Filho, 2013). 
A argumentação teórica e empírica apresentada anteriormente contribuiu para qualificar o problema de pesquisa e encaminhar seu desenho teórico-metodológico ao sinalizar para as questões norteadoras, considerando o reduzido debate sobre o tema: Como se expressa o protagonismo dos sujeitos implementadores das políticas de Estado no trânsito entre o aspecto formal das políticas e a sua materialização? São condicionados por práticas tradicionais ou processos inovadores? Verificam-se novos acordos do nível paradiplomático? Qual é o perfil sócio profissional dos sujeitos implementadores das políticas púbicas? Quais os valores que perpassam sua apreensão sobre a política de saúde e assistência social? Em que medida sua cultura política interfere em suas funções? Quais são as mediações democráticas possíveis? No caso dos assistentes sociais, qual é a relação entre as competências e atribuições profissionais privativas e as exigidas pela dinâmica da gestão? Como é a interação entre os agentes públicos locais com os demais níveis hierárquicos? Há articulação entre os agentes estatais com os similares do outro lado da fronteira? Quais as formas de apropriação das políticas e outros dispositivos relativos à fruição do direito à saúde e à assistência social? Como são reconstruídas as relações com os agentes de ponta do sistema? Como os agentes de ponta interpretam a relação com os agentes de médio escalão? Sintetizando, quais os determinantes éticos, sociais, políticos e técnico-operativos que influenciam positiva ou negativamente a cooperação transfronteiriça no contexto fronteiriço internacional dos países do MERCOSUL.

Estas questões determinaram as metas para a consecução dos objetivos desta proposta, assim formalizadas: - Descrever a organização institucional dos sistemas locais de saúde e assistência social no seu aspecto administrativo, organogramas e competências funcionais; - Identificar os serviços e ações prestadas pelos sistemas locais de assistência social e saúde com vistas a verificar a sua complexidade; - Recuperar a legislação transfronteiriça (legislação nacional, acordos e pactos entre os países e as decisões do MERCOSUL) no campo da saúde e assistência social; - Traçar a composição profissional e as vinculações éticas e políticas dos agentes estatais responsáveis pela materialização das políticas de saúde e assistência social em nível local; - Identificar as interações estabelecidas com a rede de atores internos e externos envolvidos com a política municipal de saúde e assistência social na dimensão transfronteiriça; - Caracterizar a dinâmica processual da ação dos agentes locais na implementação das políticas da saúde e da assistência social como favorecedora ou neutralizadora da dimensão social da cidadania; - Resgatar os 
obstáculos relacionados à implementação das políticas com vistas à cooperação transfronteiriça.

Importa ainda referenciar que se optou por uma abordagem exploratória, pois não foram localizados nos bancos de dados mais relevantes textos científicos abordando o tema em regiões fronteiriças, o que sugeriu a realização de um estudo qualitativo de casos múltiplos, reconhecendo que as fronteiras apresentam características estruturais distintas em vários aspectos. Assim, os casos escolhidos detém a possibilidade de identificar como estas características impactam na proteção socioassistencial e de saúde.

Os dados necessários para a análise pretendida serão obtidos através de pesquisa documental e entrevistas em profundidade. Os documentos, como produto de sociedade, são fontes históricas e exprimem as relações sociais e de poder da sociedade do "passadopresente e do presente-passado" (Ianni, 2011). A pesquisa documental é importante para a compreensão de uma dada conjuntura histórica, política, social e cultural e a análise dos documentos deve responder as perguntas da pesquisa e estabelecer a relação com a fundamentação teórica.

Quando um pesquisador utiliza documentos objetivando extrair dele informações, ele o faz investigando, examinando, usando técnicas apropriadas para seu manuseio e análise; segue etapas e procedimentos; organiza informações a serem categorizadas e posteriormente analisadas; por fim, elabora sínteses, ou seja, na realidade, as ações dos investigadores (SáSilva, Almeida \& Guindan, 2009, p. 4).

As legislações, regulamentações jurídico-administrativas, os serviços e ações prestados nas duas dimensões e os acordos e pactos bilaterais e trilaterais, as decisões do MERCOSUL sobre fronteiras serão resgatadas através de pesquisa documental, junto aos organismos oficiais do MERCOSUL, sites dos Ministérios Nacionais e das Secretarias de Saúde e Assistência Social dos municípios pesquisados. A centralidade a orientar a pesquisa documental serão os conceitos e conteúdos sobre cidadania social e cooperação transfronteiriças nos documentos pesquisados. Enfim, o objetivo último do resgate documental será o de identificar aspectos similares e hegemônicos nos conteúdos presente nos documentos dos países e das cidades pesquisadas.

A proposta de entrevista em profundidade privilegia a relação entre pesquisador e pesquisado, busca o diálogo entre os participantes, ou seja, "[...] constitui-se num "espaço relacional privilegiado', onde o pesquisador busca o protagonismo do participante" (Moré, 
2015 p. 127). Foram escolhidas, pois favorecem o resgate dos aspectos políticos, éticos e técnico-operativos relativos à gestão em espaços fronteiriços internacionais. Fornecem igualmente informações contextuais significativas para alcance dos objetivos propostos. A pretensão é ultrapassar os dados obtidos em estudos anteriores realizados pela equipe, visto que em nenhum deles foram utilizadas entrevistas em profundidade. Nos locais onde for impossível aprofundar a entrevista pela reconhecida reticência dos sujeitos, se utilizará um roteiro norteador.

O número de entrevistas a serem realizadas irá depender da complexidade do sistema de saúde e assistência social, abrangendo minimamente um gestor e um técnico executivo de ponta de cada uma das políticas em todas as cidades pesquisadas. O critério de saturação indicará o número de entrevistas suficientes para a análise. Os entrevistadores serão os pesquisadores de campo (dois por cidade, sendo um o responsável pelas entrevistas relacionadas ao setor saúde e outro para a política de assistência social).

Serão entrevistados os gestores e os profissionais do setor saúde e assistência social que ocupam funções classicamente relacionadas à gestão, como supervisão, controle, coordenação e planejamento. Os profissionais de ponta do sistema serão os diretamente envolvidos com a provisão e prestação de serviços (atenção/proteção básica, média e alta complexidade da assistência e saúde). Os critérios de escolha dos sujeitos de pesquisa estão condicionados à posição no organograma institucional e plano de cargos e salários. Estão previstas preliminarmente seis entrevistas com gestores de saúde, seis entrevistas com profissionais da saúde, seis entrevistas com gestores da assistência social e seis entrevistas com os profissionais da assistência social. Observa-se que estes números estão sujeitos a variações dependendo da complexidade dos sistemas locais.

A definição do campo empírico levou em consideração as especificidades da faixa de fronteira entre os países integrantes do bloco regional. Os critérios de definição quanto às cidades a serem pesquisadas foram três: 1. Cidades-gêmeas com trajetórias distintas de cooperação transfronteiriça de sistemas de saúde e assistência social, sendo que em Santana do Livramento/Rivera há um processo de integração que hora se amplia ora se retrai, dependendo dos sujeitos políticos e em andamento há vários anos; Em Bernardo de Irygoyen/Dionisio Cerqueira se tem iniciativas de integração intermitentes; Concordia e Salto mantém alto grau de cooperação no setor da educação, e as cidades da tríplice fronteira pelas suas características peculiares estarem localizadas em uma fronteira extremamente 
dinâmica e complexa; 2. Cidades com densidades populacionais distintas. A tipologia de classificação do porte dos municípios foi baseada na indicação do antigo Ministério de Desenvolvimento Social do Brasil (Brasil, 2017) $)^{5}$; 3. O interesse do Instituto Social do Mercosul, enquanto apoio institucional do projeto, em abranger as fronteiras entre todos os países do bloco regional.

As cidades gêmeas que vão ser pesquisadas são: Puerto Iguazú e Bernardo de Irigoyen (Argentina); Foz do Iguaçu, Dionísio Cerqueira, Santana do Livramento e Guaíra (Brasil); Ciudad del Este, Salto do Guairá (Paraguay) e Rivera (Uruguay). Pelo fato do estudo se realizar em quatro países, alguns cuidados adicionais, próprios de estudos multicêntricos, devem ser tomados, sendo necessário certo grau de uniformidade dos procedimentos de pesquisa e segurança quanto aos dados a serem coletados. Para assegurar a validade dos resultados, os estudos multicêntricos precisam ser idênticos e conduzidos da mesma maneira em cada um dos locais onde se realiza, ainda que o planejamento da pesquisa deva considerar contextos locais (Dhai, 2005).

A atribuição de responsabilidades da equipe de pesquisa levou em conta o fato do estudo ser realizado em quatro países. A coordenação do projeto compreenderá duas dimensões distintas, embora interligadas. A primeira se refere aos aspectos burocráticos-administrativos compreendendo a organização da gestão financeira, construção de instrumentos de controle operacional, administração das despesas (diárias, passagens, material de consumo), acompanhamento do cronograma de execução financeira. A segunda dimensão diz respeito aos aspectos técnicos relativos às finalidades últimas previstas e compreende a articulação interinstitucional, organização de seminários da equipe de pesquisas para encaminhamentos teóricos e operativos do projeto, seleção e capacitação de pesquisadores de campo, supervisão da coleta e sistematização de dados, produção e organização da metodologia de análise, organização dos pesquisadores e auxiliares de pesquisa para elaboração do relatório final. As atividades realizadas pela equipe de pesquisa contemplam: nivelamento do patamar de conhecimento sobre os referenciais teóricos do presente projeto; atualização dos dados contextuais das cidades-gêmeas; resgate da organização jurídico/política e administrativa do sistema local de saúde e assistência social de cada uma das cidades que se constituem em campo de estudo; construção dos instrumentos de

Municípios de Pequeno Porte I (até 20.000 habitantes): Bernardo de Irigoyen e Dionísio Cerqueira; Municípios de Pequeno Porte II (20.001 a 50.000 habitantes): Posadas, Guaíra e Salto del Guairá: Municípios de Médio Porte (50.001 a 100.000 habitantes): Puerto Iguazu, Encarnación e Santana do Livramento; Municípios de Grande Porte (100.001 a 900.000 habitantes): Foz do Iguaçu, Concordia, Salto, Rivera e Ciudad del Este. 
pesquisa para coleta dos dados e elaboração do manual do pesquisador.

Os pesquisadores coordenadores serão os responsáveis pela coordenação, em cada país, pela coleta e sistematização de dados, contribuição na construção dos referenciais analíticos, monitoramento dos pesquisadores de campo, análise preliminar dos dados em cada um dos países, elaboração de relatórios parciais e colaboração no relatório final.

Os pesquisadores de campo farão a pesquisa documental, realização e transcrição das entrevistas e deverão colaborar na sistematização dos dados, através do uso das ferramentas do Software WebQDA, que será utilizado como ferramenta de apoio da análise da pesquisa. Optou-se por esta ferramenta pela viabilidade de interlocução dos pesquisadores de campo e coordenadores da pesquisa durante todas as etapas do processo investigativo. A inserção do conteúdo dos documentos no software WebQDA vai viabilizar confirmar ou excluir determinadas categorias, pois a ferramenta possibilita um olhar criterioso sobre o material selecionado. Todo esse processo vai qualificar a fase de categorização, destacando-se que no processo de análise dos documentos e das entrevistas pode ser necessário a construção de sub-categorias para responder as questões da pesquisa. O processo de categorização dos dados levará em consideração a consistência e frequência dos fragmentos de textos e núcleos de sentido.

Indicamos que o estudo terá três etapas. Primeira etapa: dedicada à seleção de textos para referência teórica que vão orientar não apenas o desenho mais detalhado dos procedimentos metodológicos, incluindo aqui a construção dos instrumentos de coleta de informações, como também, o aprofundamento do quadro de referência teórica da pesquisa. Segunda etapa: compreenderá a coleta dos dados secundários, com a identificação e seleção dos documentos que vão ser disponibilizados para todos os pesquisadores através de armazenamento on-line, favorecendo a troca constante de informações. Terceira etapa: sistematização do material coletado, realizando a transcrição das entrevistas quando gravadas e a inserção no software WebQDA. Contempla, ainda, a análise dos dados segundo o roteiro proposto e expresso nas questões norteadoras do referencial teórico e, por fim, a preparação dos quadros sínteses. 


\section{CONCLUSÕES}

Conforme indicado anteriormente, as opções metodológicas decorrem das questões a serem abordadas, no caso específico os sujeitos políticos do âmbito governamental local (gestores e profissionais dos setores da saúde e assistência social), face a cooperação transfronteiriça e a dimensão social da cidadania 6 e, expressas nos objetivos e metas previstas. Assim, o desenho metodológico apresentado é um desafio para articular os objetivos, questões norteadoras e metas. Um procedimento metodológico pertinente para a coleta de informações necessárias em regiões com alta complexidade institucionais, políticas econômicas e sociais, implicaria na construção de roteiros intrinsicamente relacionadas para o alcance dos objetivos, favorecendo análises consistentes com escopo da pesquisa. Para isso, além de critérios e objetivos claros, é necessário que os pesquisadores tenham uma constante atenção na aplicação dos instrumentos de pesquisa. Destaca-se a necessária competência do pesquisador na escolha das categorias que serão colocados para análise no software WebQDA. A utilização do software WebQDA vai permitir a organização dos documentos que serão analisados, a interligação dessas fontes e a codificação das categorias, o que vai possibilitar a construção da primeira árvore de categorias. A inserção do conteúdo dos documentos no software WebQDA e das entrevistas viabilizará confirmar ou excluir determinadas categorias, pois a ferramenta possibilita um olhar criterioso sobre o material selecionado. Todo esse processo vai qualificar a fase de categorização, destaca-se que no processo de análise dos documentos pode evidenciar a necessidade de construção ou não de sub- categorias para responder as questões da pesquisa. Essas indicações são apresentadas como possibilidades de confiabilidade nos resultados da pesquisa.

\section{REFERÊNCIAS}

Aikes, S., \& Rizzotto, M. L. F. (2018). Integração regional em cidades gêmeas do Paraná, Brasil, no âmbito da saúde. Cad. Saúde Pública, 34(8).

Borraz, O., \& Guiraudon, V. (2010) Changer La societé. Politique publique. Paris: Presses de la Fondation Nationale des Sciences Politiques.

Cavalcante, P. L., \& Lotta, G. S. (2015). Burocracia de médio escalão: perfil, trajetória e atuação. Brasília: ENAP.

\footnotetext{
${ }^{6}$ Cidadania Social ou a dimensão social da cidadania é entendida como o conjunto de direitos e obrigações que possibilita a participação igualitária de todos os membros de uma comunidade nos seus padrões básicos de vida. Em sociedades capitalistas democráticas há uma permanente tensão entre a cidadania individual e a dimensão social da cidadania visto implicar em ajustes entre interesses contraditórios entre capital e trabalho.
} 
Cavalcante, P. L., Camões, M. R. S., \& Knop, M.N.H. (2015). Burocracia de médio escalão nos setores governamentais: semelhanças e diferenças. In: Cavalcante, P. L., \& Lotta, G. S. (orgs.). Burocracia de médio escalão: perfil, trajetória e atuação. Brasília: ENAP.

Dhai, A. (2005). A revisão ética nos comitês. In: Diniz, D., Guilhem, D. \& Schuklenk, U. (Orgs.). Ética na pesquisa: experiência de treinamento em países sul-africanos. Brasília: Letras Livres/Editora UnB.

lanni, O. (2011). A construção da categoria. Revista HISTEDBR On-Line. v. 11 (41e), 397-416. Recuperado a partir de https://periodicos.sbu.unicamp.br/ojs/index.php/histedbr/article/view/8639917.

Mégie, A. (2010) Mise en Oeuvre. In: Boussaguet, L.; Jacquot, S.; Ravinet, P., eds. Dictionnaire des politiques publiques. Paris: Presses de Sciences Po, 343-350.

Moré, C. L. O. O. (2015). A “entrevista em profundidade" ou "semiestruturada", no contexto da saúde. Dilemas epistemológicos e desafios de sua construção e aplicação. Atas CIAIQ2015. Investigação Qualitativa em Ciências Sociais. v. 3. Recuperado a partir de https://proceedings.ciaiq.org/index.php/ciaiq2015/article/view/158/154

Oliveira, V. E., \& Abrucio, F.L., (2011). Entre a política e a burocracia: a importância dos burocratas de nível médio para a produção de políticas públicas em saúde e educação. In: Anais Encontro Anual da ANPOCS, 35, 24-28, Caxambu, Minas Gerais, Caxambu: Anpocs.

Sá-Silva, J. R., Almeida, C. D., \& Guindani, J. F., (2009). Pesquisa documental: pistas teóricas e metodológicas. Revista Brasileira de História \& Ciências Sociais. v. 1, n. 1, Recuperado a partir de https://periodicos.furg.br/rbhcs/article/view/10351/0

Souza Filho, R. de., (2013). Gestão Pública \& Democracia: a burocracia em questão. Rio de Janeiro: Editora Lumen Juris.

Telles, V. (1994). Sociedade civil, direitos e espaços públicos. In Villas-Boas, R. (org.). Participação popular nos governos locais. São Paulo: Pólis, 43-53.

Tumelero, S. M., (2015). Estado, produção do espaço e intersetorialidade: Crítica e criação na implementação de políticas públicas. Tese Programa de Pós-Graduação em Serviço Social. Universidade Federal de Santa Catarina. Recuperado a partir de https://repositorio.ufsc.br/xmlui/bitstream/handle/123456789/160623/338083.pdf?sequence=1\&isAllowed=y

Zittoun, P. (2013). La fabrique politique dês politiques publique. Paris: Presses de Science Pol. 